\title{
PERFIL SOCIOECONÔMICO DE ALUNOS DO PROUNI E EX-BENEFICIÁRIOS DO PROGRAMA BOLSA FAMÍLIA DE UMA UNIVERSIDADE SEM FINS LUCRATIVOS DE SÃO PAULO
}

\author{
ANDRÉ PIRES \\ Paulo Cesar Ricci Romão \\ Pontifícia Universidade Católica de Campinas (PUC- Campinas), Campinas, São \\ Paulo, Brasil
}

\begin{abstract}
Resumo: Este artigo objetiva apresentar, de maneira descritiva, o perfil socioeconômico de um conjunto reduzido de pessoas que foi beneficiário do Programa Bolsa Família (PBF) e que ingressou numa Universidade privada sem fins lucrativos do estado de São Paulo pelo Prouni. Os números do cadastro dessa Universidade indicam que aqueles que recebem ou já receberam recursos do PBF perfazem o grupo mais vulnerável em termos socioeconômicos. Ao buscar conhecer o perfil socioeconômico dos alunos originários do Programa Bolsa Família após a Educação Básica, o artigo oferece contribuições no sentido de evidenciar o acesso ao ensino superior de um grupo social até então distante dessa possibilidade. Todavia, o custo para isso se mostra particularmente alto quando se considera somente os bolsistas e ex-bolsistas do Programa Bolsa Família.
\end{abstract}

Palavras-chave: Prouni. Bolsa Família. Ensino Superior. Pobreza.

INTRODUÇÃO

O Programa Bolsa Família (PBF) é um programa de transferência de renda condicionado do governo federal, criado em 2003 a partir da unificação e ampliação de outros programas existentes (ROCHA, 2013; SILVA; YAZBEK; DIGIOVANNI, 2007; FONSECA, 2001). Seu desenho prevê o enfrentamento da pobreza a partir da articulação de ações em curto e longo prazos. Em curto prazo, a transferência monetária direta às famílias e aos indivíduos com valores variados, a depender da renda familiar ou individual, número e idade dos filhos até 17 anos. Em longo prazo, o Programa aposta no cumprimento das condicionalidades em saúde e educação como forma de incrementar o acesso aos serviços públicos, assim como no capital humano dos beneficiários'.

Como se pode notar, a educação ocupa lugar central no desenho do PBF para enfrentar a chamada transmissão da pobreza intergeracional. A concessão do benefício está condicionada ao cumprimento de frequência escolar mínima de $85 \%$ para crianças e jovens entre 6 e 15 anos (valor 10 pontos percentuais acima do exigido dos demais alunos, de acordo com a Lei de Diretrizes e Bases da Educação Brasileira) e de $75 \%$ para adolescentes entre 16 e 17 anos. 
Muitos trabalhos têm apontado os benefícios materiais e simbólicos que a participação no $\mathrm{PBF}$ tem proporcionado aos beneficiários, às suas famílias e ao desenvolvimento econômico (SILVA, 2013; ABRAHÃO; MOSTAFA; HERCULANO, 2011; REGO; PINZANI, 2013). Com relação ao cumprimento da frequência em educação, estudos apontam para a efetividade da exigência de frequência até 17 anos, na medida em que os beneficiários do programa apresentam maiores proporções em termos de porcentagem de matrículas, taxas de distorção idade/série, entre outros benefícios (CIRENO; SILVA; PROENÇA, 2013; PIRES, 2013b; MELO; DUARTE, 2010; GONÇALVES; MENICUCCI; AMARAL, 2017).

Se, por um lado, há um conjunto de reflexões que busca analisar os indicadores educacionais das crianças e jovens participantes do PBF (até 17 anos), por outro, não se encontra muitos trabalhos que apresentem informações sobre os percursos educacionais desses jovens e adultos depois que eles atingem a idade limite para a participação no programa (Questão de Oportunidade, 2017). Pires (2013b), por exemplo, evidenciou queda abrupta da frequência escolar de beneficiários do Programa após completarem 18 anos.

De fato, é um grupo muito reduzido de pessoas que, tendo participado do Programa Bolsa Família, ingressa no ensino superior. A título de ilustração, informações do Censo Demográfico de 2010 sobre a Região Metropolitana de Campinas, que congregava naquele ano 19 municípios, com população de cerca de 2 milhões de pessoas, indicaram que somente $0,4 \%$ dos jovens entre 18 e 29 anos que haviam recebido o PBF frequentava Curso Superior ou Pós-Graduação. Considerando o conjunto de jovens na mesma faixa etária, mas que não foi beneficiário do programa, essa porcentagem eleva-se para 15,1\%. Se atentarmos para as informações presentes no Cadastro Único para Programas Sociais (CadÚnico) do município de Campinas, das 27.251 pessoas que recebiam o PBF em 2016, na faixa etária entre 18 e 34 anos, somente $0,3 \%$ cursava Curso Superior ou PósGraduação.

Este artigo objetiva apresentar, de maneira descritiva, o perfil socioeconômico desse conjunto reduzido de pessoas que era beneficiário do Programa Bolsa Família em 2016, ano em que esses alunos estavam matriculados em cursos de graduação de uma Universidade privada do estado de São Paulo. O ingresso desses estudantes no ensino superior deu-se a partir de outra política focalizada em pessoas de baixa renda do governo federal, o Programa Universidade para Todos (Prouni). Juntamente a outras iniciativas voltadas às Instituições privadas ou públicas de educação superior, tais como o FIES (Fundo de Financiamento aos Estudantes de Ensino Superior), criado em 2001; o REUNI (Programa de Apoio a Planos de Reestruturação e Expansão das Universidades Federais), instituído em 2007; o Programa de Ações Afirmativas para a População Negra nas Instituições Federais e Estaduais de Educação Superior (UNIAFRO), de 2008; e, finalmente, a Lei no 12.711 de 12 de agosto de 2012, conhecida como a "lei de cotas", essas ações contribuíram para o ingresso e permanência de uma população historicamente excluída do ensino superior (CASALI; MATTOS, 2015)2.

O Programa Bolsa Família e o Prouni possuem critérios de elegibilidade, públicosalvo distintos e são geridos por diferentes Ministérios ${ }^{3}$. No entanto, ambos (definidos por 
PIRES, A.; ROMÃO, P. C. R.

critérios diversos) se destinam a pessoas de baixa renda e pode-se inferir que são complementares com relação à cobertura por idade. O PBF tem como um de seus públicos-alvo crianças e jovens de até 17 anos, dos quais se exige frequência escolar mínima, e o Prouni se destina a estudantes universitários que, num sistema educacional seriado como brasileiro, iniciam o curso de graduação com 17 ou 18 anos. A linha de corte para receber o benefício do PBF é de $\mathrm{R} \$ 170$ (cento e setenta reais) per capita.

O Programa Universidade para Todos (Prouni) se destina "à concessão de bolsas de estudo integrais e bolsas de estudo parciais de $50 \%$ (cinquenta por cento) ou de $25 \%$ (vinte e cinco por cento) para estudantes de cursos de graduação em instituições privadas de ensino superior, com ou sem fins lucrativos" (Lei n ${ }^{\circ} 11.096$ de 13 de janeiro de 2005). A bolsa de estudo integral pode ser conferida somente aos alunos cuja renda familiar mensal per capita não exceda o valor de até 1 (um) salário-mínimo e 1/2 (meio). Já as bolsas parciais são concedidas a alunos cuja renda familiar mensal per capita não exceda o valor de até 3 (três) salários-mínimos. Para a concessão de bolsas, integral ou parcial, é preciso que o aluno tenha cursado o ensino médio completo em escola da rede pública ou em instituições privadas na condição de bolsista integral. O programa também confere bolsas de estudo a estudantes com deficiência e a professores da rede pública que atuam na educação básica. Esses últimos não necessitam comprovar renda para participar do programa. A seleção do curso de graduação e da IES é feita por sistema do Ministério da Educação, gerenciador do Prouni, mediante as opções dos cursos selecionados e a nota obtida no Exame Nacional do Ensino Médio (Enem). Entre 2005 e 2014 foram concedidas 1,3 milhão de bolsas para Instituições de Ensino Superior em todo o país, com mais de 450 mil estudantes formados nas mais diversas áreas do conhecimento. Tal como observa Dilvo Ristoff:

Para que se tenha uma ideia do significado deste número, basta lembrar que todas as universidades federais juntas graduam por ano cerca de 100 mil estudantes. Ou seja, o Prouni, durante os seus dez primeiros anos de história, graduou o equivalente a quatro gerações e meia de estudantes formados nas universidades (RISTOFF, 2016, p. 21).

Almeida (2014), ao traçar um perfil socioeconômico dos alunos bolsistas que compõem seu corpus de análise, demonstra a importância da análise metódica dos dados pertinentes aos bolsistas do Prouni para uma compreensão maior sobre o próprio programa, seus impactos e efeitos. De igual maneira, Costa (2008); Sampaio, Limongi e Torres (2000); e Santos (2001) chamam a atenção para a necessidade da análise do perfil socioeconômico desses alunos como ferramenta essencial para a compreensão não só do Programa Universidade para Todos, mas do sistema de ensino superior no Brasil.

\section{INFORMAÇÕES SOBRE CADASTRO}

De acordo com as regras do Prouni (Art $3^{\circ}$ da Lei $n^{\circ} 11.096$ de 13 de janeiro de 2005), a seleção dos alunos para o programa é feita em dois momentos. O Ministério da Educação realiza uma pré-seleção a partir das informações socioeconômicas e dos resultados do Enem, cujos critérios foram mencionados nos parágrafos anteriores. Cabe à 
IES, em etapa final da seleção, aferir as informações prestadas pelos alunos, além de estabelecer seus próprios critérios. No caso da Universidade em questão, a seleção interna é também feita em dois momentos. No primeiro, são analisadas informações fornecidas pelo candidato a partir do preenchimento de uma "Ficha do Aluno/Candidato", que contém um conjunto de informações socioeconômicas dele e de sua família, tais como trabalho, rendimentos, trajetória escolar, local de residência, entre outras. É realizada também uma entrevista individual, na qual o candidato deve apresentar sua ficha devidamente preenchida e cópia de todos os documentos comprobatórios requeridos. A cada ano, todos os bolsistas da Universidade devem atualizar as suas informações cadastrais. A partir de contatos estabelecidos com os gestores do órgão responsável pelo cadastro e acompanhamento dos alunos prounistas, foi possível inserir uma questão específica sobre a participação no Programa Bolsa Família no processo de recadastramento anual dos bolsistas dessa Universidade ${ }^{4}$.

De um total aproximado de 18.000 alunos matriculados em cursos de graduação em 2016, o cadastro da Universidade possuía informações de 2.073 alunos bolsistas do Prouni (11\% do total, aproximadamente). Desse conjunto, 120 alunos $(5,8 \%$ do total de bolsistas) fazem parte de grupos familiares que recebem ou já receberam benefício do Programa Bolsa Família. A instituição não concedeu bolsas do Prouni na modalidade parcial, sendo todas integrais.

Tabela 1: Distribuição dos alunos do Prouni segundo participação no PBF

\begin{tabular}{lr|r|} 
& $\mathrm{N}$ & $\%$ \\
\hline Bolsa Família & 120 & 5,8 \\
Demais alunos & 1.953 & 94,2 \\
Total Prouni & 2.073 & 100,0 \\
\hline
\end{tabular}

Fonte: Cadastro de Informações Sociais da Universidade (elaboração dos autores)

Os números do cadastro indicam que aqueles que recebem ou já receberam recursos do PBF perfazem, dentre os mais pobres da Universidade, o grupo mais vulnerável em termos socioeconômicos. Como bem sintetizou uma aluna do curso de Direito, quando perguntada se havia mais alguém que conhecia em sua sala que recebia o PBF:

Não, tinha pessoas do PROUNI, mas não da situação de precariedade como a minha [que recebe o Bolsa Família] (Entrevistada, Direito, 43 anos).

Veremos a seguir que receber ou ter recebido Bolsa Família faz com que aumentem as chances de ter cursado o ensino médio somente em escola pública, de ter pai ou mãe com escolaridade inferior ao grupo dos demais alunos, com destaque para a elevada proporção, seja de pais, seja de mães, com ensino fundamental (completo ou 
PIRES, A.; ROMÃO, P. C. R.

incompleto). No tocante às marcações de cor/raça, a porcentagem de estudantes que recebem ou já receberam o PBF que se declararam pretos ou pardos é mais do que o dobro do verificado entre os demais alunos prounistas. Destaca-se que os alunos bolsistas ingressam na Universidade com uma idade média acima daquela esperada em um sistema de ensino seriado como o brasileiro, a saber, entre 17 e 18 anos. Tais números retratam as dificuldades enfrentadas por boa parte desses alunos no percurso escolar anterior ao ingresso na Universidade, em termos, por exemplo, de interrupções (voluntárias e involuntárias) dos estudos, reprovações, entre outros fatores que serão mencionados na análise dos números. O percurso escolar anterior dos alunos bolsistas da Universidade indica que a maioria frequentou ensino médio em escola pública, número que tende a crescer quando se considera os beneficiários e ex-beneficiários do PBF. No tocante à renda do aluno, os números evidenciam as dificuldades financeiras desse conjunto de estudantes, com especial ênfase para os do grupo PBF: os alunos que participam/participaram do PBF possuem renda mensal $12 \%$ inferior em relação aos demais bolsistas do Prouni. Além disso, veremos que os dados do cadastro sugerem que os cursos de graduação do grupo PBF tendem a ser os menos prestigiosos (em termos econômicos e simbólicos) das suas respectivas áreas de conhecimento.

\section{ORIGENS}

Tabela 2: Distribuição dos alunos do Prouni, segundo participação no $\mathrm{PBF}$, por sexo, raça/cor e estado civil

\begin{tabular}{|c|c|c|c|}
\hline & & \multicolumn{2}{|c|}{ Prouni } \\
\hline & & Bolsa Família & Demais alunos \\
\hline \multirow{3}{*}{ Sexo } & Feminino & $67,5 \%$ & $60,4 \%$ \\
\hline & Masculino & $32,5 \%$ & $39,5 \%$ \\
\hline & Não Declarado & $0,0 \%$ & $0,1 \%$ \\
\hline \multirow{6}{*}{ Raça Cor } & Amarela & $0,8 \%$ & $0,3 \%$ \\
\hline & Branca & $45,0 \%$ & $73,8 \%$ \\
\hline & Indígena & $0,0 \%$ & $0,1 \%$ \\
\hline & Não Declarada & $0,0 \%$ & $0,5 \%$ \\
\hline & Parda & $34,2 \%$ & $17,4 \%$ \\
\hline & Preta & $20,0 \%$ & $8,0 \%$ \\
\hline
\end{tabular}




\begin{tabular}{llr|r} 
& Casado & $5,8 \%$ & $5,0 \%$ \\
\cline { 2 - 4 } Estado Civil & Separado ou divorciado & $0,8 \%$ & $1,0 \%$ \\
\cline { 2 - 4 } & Não declarado & $0,0 \%$ & $0,1 \%$ \\
\cline { 2 - 4 } & Solteiro & $90,8 \%$ & $91,9 \%$ \\
\cline { 2 - 4 } & União Estável/Outro & $2,5 \%$ & $2,0 \%$ \\
\hline \hline
\end{tabular}

Fonte: Cadastro de Informações Sociais da Universidade (elaboração dos autores)

Comecemos com informações sobre o sexo dos bolsistas da Universidade. A prevalência de mulheres em relação aos homens nos dois segmentos considerados (superior a $60 \%$ ) é até certo ponto esperada, uma vez que o percentual de mulheres no ensino superior como um todo é maior (de acordo com o Censo da Educação Superior de 2016, as mulheres representam 57,2\% dos estudantes matriculados em cursos de graduação) $)^{5}$. Todavia, quando se leva em consideração alunos mais pobres que ingressaram no ensino superior, fatores de ordem econômica, cultural e curriculares fazem com que estudantes pobres do sexo masculino tenham que largar os estudos antes de completar os ciclos escolares, sobretudo o ensino médio. Em muitas situações, os custos de oportunidades para o estudo formal é maior para os meninos do que para as meninas (MELO; DUARTE, 2010). A título de ilustração, a média da distribuição por sexo dos alunos prounistas (com bolsa integral e parcial), que participaram do Exame Nacional de Desempenho de Estudantes (Enade) em 2013, 2014 e 2015 no município do estado de São Paulo, onde se localiza a Universidade pesquisada, registrou $60,5 \%$ de mulheres e $39,5 \%$ de homens. A utilização de diferentes anos do Enade se justifica pelo fato de que a cada ano são avaliados alunos de diferentes cursos de graduação. Optamos, nesse sentido, por apresentar informações sobre os três últimos anos disponíveis para esse exame no sítio institucional do Inep ${ }^{6}$. Desde o final da década de 1990, dados socioeconômicos do chamado Provão já apontavam para uma maior proporção de alunas (mulheres com mais de 25 anos) como maioria no ensino superior privado (SAMPAIO; LIMONGI; TORRES, 2000).

Se por um lado verifica-se que as mulheres compõem a maioria dos bolsistas do Prouni, a tabela 2 indica que a porcentagem de mulheres em relação aos homens de beneficiários do PBF na Universidade pesquisada é ainda maior. No caso em questão, $67,5 \%$ em favor das mulheres do PBF, ante $60,4 \%$ para as demais bolsistas do Prouni. Uma hipótese para explicar tal diferença pode ser traçada a partir das condições econômicas desse grupo, em geral, piores em relação aos demais alunos do Prouni em termos de rendimentos, algo que trataremos adiante. Em situações de maior privação econômica, a pressão para a obtenção de renda aumenta, em detrimento, muitas vezes, da possibilidade de permanecer na escola. Trata-se de um processo que não se inicia no ensino superior e que parece atingir com maior intensidade os homens.

Além disso, e paradoxalmente, a questão da maternagem pode ter influência indireta nesse processo. Como já mencionado, Pires (2013b) indicou queda abrupta da frequência escolar de beneficiários do PBF para a região Metropolitana de Campinas 
PIRES, A.; ROMÃO, P. C. R.

quando eles completam 18 anos. $O$ autor demonstrou que essa queda atingia de maneira mais intensa mulheres que participavam do PBF, em função do fato de que cabe a elas a tarefa de cuidar dos filhos. Assim, as mulheres que permanecem na escola e passam com sucesso pelos diversos ciclos escolares conseguem escapar com maior êxito dos "destinos" de origem esperados para sua condição socioeconômica, na qual a evasão escolar, seja para obtenção de renda, seja para cuidar dos filhos, é muito mais a regra do que a exceção.

No tocante às marcações cor/raça, os números da tabela 2 indicam que a porcentagem de pretos/pardos do grupo dos alunos do Bolsa Família é duas vezes superior à dos demais alunos do Prouni, 54,2\% e 25,3\% respectivamente ${ }^{7}$. A porcentagem de brancos também se diferencia de maneira acentuada quando se considera os alunos do Bolsa Família e demais prounistas. Nesse caso, a diferença em favor dos alunos somente Prouni é de 28,8 pontos percentuais, perfazendo um total de $73,8 \%$, ante $45 \%$ de brancos do Bolsa Família. Fazendo uma comparação, a média aritmética das respostas dos alunos que prestaram o Enade de 2013 a 2015, no município onde se localiza a Universidade em questão, de acordo com a auto atribuição de cor e raça, apontou para um contingente de $74,7 \%$ de brancos e de $21,8 \%$ de pardos, mulatos e negros ${ }^{8}$. Os números apresentados sugerem que $o$ Prouni, notadamente para aqueles que participaram do PBF, tem contribuído para a inclusão de um contingente de pessoas negras/pardas no ensino superior, historicamente excluídas desse acesso. Cabe lembrar que o número de bolsistas denominados brancos ainda é bastante superior: entre 2005 e 2011, por exemplo, o percentual de bolsistas que se definiam como brancos perfazia $47,5 \%$ do total de bolsistas do país (ALMEIDA, 2014). Assim, a despeito dos avanços indicados nesta e em outras investigações, há ainda um bom caminho a percorrer em direção a um maior equilíbrio na composição cor/raça nos campi universitários brasileiros quando se considera o conjunto da população. É forçoso ainda constatar que:

Os estudantes pretos, com $6 \%$ de representação no campus, têm $2 \%$ a menos do que representam na sociedade brasileira e os pardos, que representam $43 \%$ da população brasileira, têm representação média de apenas $24 \%$ na graduação, o que significa dizer que é o grupo menos bem representado (RISTOFF, 2016, p. 42).

Considerando o estado civil, os números indicam a prevalência, com mais de $90 \%$ em ambos os casos considerados, de estudantes solteiros. Porém, verifica-se uma ligeira vantagem para alunos do PBF com algum tipo de união (casado/união estável outro), 8,3\% e 7,0\%. Este é um indicativo, a ser tratado adiante, de que os alunos do PBF acabam tendo maiores responsabilidades para arcar com o sustento de suas famílias. 
Tabela 3: Distribuição dos alunos do Prouni, segundo grau de instrução do pai e mãe

\begin{tabular}{|c|c|c|c|}
\hline \multicolumn{4}{|c|}{ Prouni } \\
\hline & & Bolsa Família & Demais alunos \\
\hline \multirow{7}{*}{$\begin{array}{c}\text { Grau de Instrução } \\
\text { do Pai }\end{array}$} & "Ensino Fundamental 1 ao 5 ano 1 a 4 série & $19,2 \%$ & $5,2 \%$ \\
\hline & Ensino Fundamental 6 ao 9 ano 5 a 8 série & $19,2 \%$ & $18,6 \%$ \\
\hline & Ensino Médio & $15,0 \%$ & $26,9 \%$ \\
\hline & Ensino Superior Graduação & $0,8 \%$ & $6,9 \%$ \\
\hline & Pós-graduação & & \\
\hline & Não estudou/Nenhuma & $1,7 \%$ & $0,3 \%$ \\
\hline & Não sei/Sem informação & $43,3 \%$ & $41,4 \%$ \\
\hline \multirow{7}{*}{$\begin{array}{c}\text { Grau de Instrução } \\
\text { da Mãe }\end{array}$} & Ensino Fundamental 1 ao 5 ano 1 a 4 série & "15,8\% & 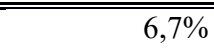 \\
\hline & Ensino Fundamental 6 ao 9 ano 5 a 8 série & $27,5 \%$ & $24,7 \%$ \\
\hline & Ensino Médio & $34,2 \%$ & $39,7 \%$ \\
\hline & Ensino Superior Graduação & $8,3 \%$ & $11,9 \%$ \\
\hline & Pós-graduação & $0,0 \%$ & $0,2 \%$ \\
\hline & Não estudou/Nenhuma & $1,7 \%$ & $0,3 \%$ \\
\hline & Não sei/Sem informação & $12,5 \%$ & $16,6 \%$ \\
\hline
\end{tabular}

Fonte: Cadastro de Informações Sociais da Universidade (elaboração dos autores)

Atentemos para a escolaridade dos pais. A comparação entre os números dos alunos prounistas permite aferir que aqueles que participaram do PBF são provenientes de famílias com pai e mãe com menor instrução. Em termos porcentuais, $38 \%$ dos pais e 43\% das mães dos alunos do grupo PBF possuem somente ensino fundamental (completo/incompleto), ante $23 \%$ e $31 \%$ dos demais alunos, respectivamente. Quando se considera somente o ensino até o $5^{\circ}$ ano ( $4^{\mathrm{a}}$ série), observa-se desvantagem para os alunos do PBF (14 pontos percentuais para a escolaridade dos pais e 9 pontos percentuais para a escolaridade das mães). É importante considerar a elevada porcentagem de estudantes que não souberam indicar o grau de instrução do pai (acima de $40 \%$ em ambos os casos), número que sugere que muitas dessas famílias são chefiadas somente por mulheres, sem a presença de pais.

Na outra ponta, observa-se um contingente até certo ponto elevado de pais, e sobretudo de mães, com curso superior para os alunos somente Prouni, $8,3 \%$ e $12,0 \%$. Quando se leva em conta somente os alunos beneficiários do PBF, a porcentagem de pais com esse grau de instrução diminui para menos de $1 \%(0,8 \%)$, e para as mães para quase 
PIRES, A.; ROMÃO, P. C. R.

metade, 6,9\%. Entretanto, ao verificarmos esse contingente de genitores com curso superior, tomados em conjunto os números sugerem que os estudantes do Prouni e, em maior grau, os que também foram beneficiários do PBF, fazem parte de arranjos familiares nos quais eles são, muitas vezes, os primeiros a cursar o ensino superior em suas famílias ${ }^{9}$. Corrobora esse entendimento os dados do Enade entre 2013 e 2015, que, na média, indicam que $50 \%$ dos estudantes bolsistas do Prouni do município de Campinas fazem parte de famílias nas quais eles são os primeiros a concluir um curso superior. Quando consideradas as médias de todos os alunos desse município para esses mesmos anos, a porcentagem cai para $30 \%$.

Tabela 4: Distribuição dos alunos do Prouni segundo distância (em $\mathrm{km}$ ) do local de origem do grupo familiar em relação ao município onde se localiza a Universidade

\begin{tabular}{|c|c|c|c|}
\hline & & Prou & \\
\hline & & Bolsa Família & Demais alunos \\
\hline & Até $100 \mathrm{KM}$ & $71,7 \%$ & $81,8 \%$ \\
\hline & $101-200 \mathrm{KM}$ & $6,7 \%$ & $8,1 \%$ \\
\hline Cidade de Origem & $201-300 \mathrm{KM}$ & $25 \%$ & $37 \%>2>0$ \\
\hline do urupo raminiar & $301-500 \mathrm{KM}$ & $2,5 \%$ & $2,9 \%$ \\
\hline & Acima de $500 \mathrm{KM}$ & $15,8 \%$ & $3,2 \%$ \\
\hline & Sem Informação & $0,8 \%$ & $0,3 \%$ \\
\hline
\end{tabular}

Fonte: Cadastro de Informações Sociais da Universidade (elaboração dos autores)

As informações da Tabela 4 mostram que a maioria dos estudantes do Prouni da Universidade pesquisada, incluídos os do grupo PBF, provém de famílias cujo local de origem se situa a menos de $100 \mathrm{~km}$ do município onde se localiza a instituição de ensino superior. Todavia, chama atenção a elevada porcentagem $(15,8 \%)$ de estudantes do PBF cujas famílias são provenientes de locais distantes, acima de $500 \mathrm{~km}$, do município em questão. Esse é um dado a corroborar outros trabalhos (PIRES, 2012; PIRES, 2008) que indicaram contingente expressivo de beneficiários do $\mathrm{PBF}$, residentes em áreas urbanas, que experienciaram processos migratórios. Das 102.942 pessoas cadastradas no Cadúnico que recebiam o PBF em 2016 no município de Campinas, 35,8\% nasceram fora do Estado de São Paulo.

\section{ENSINO MÉDIO E INGRESSO NO ENSINO SUPERIOR}


Tabela 5: Distribuição dos alunos do Prouni segundo tipo de escola que frequentaram no Ensino Médio, trabalho e idade no ingresso

\begin{tabular}{|c|c|c|c|}
\hline & & \multicolumn{2}{|c|}{ Prouni } \\
\hline & & Bolsa Família & Demais alunos \\
\hline \multirow{8}{*}{ Ensino Médio } & EJA & $0,0 \%$ & $0,3 \%$ \\
\hline & Fundação & $0,0 \%$ & $0,1 \%$ \\
\hline & Particular & $3,3 \%$ & $5,4 \%$ \\
\hline & Particular com Bolsa & $1,7 \%$ & $2,1 \%$ \\
\hline & Particular e Pública & $0,8 \%$ & $1,3 \%$ \\
\hline & Pública & $90,8 \%$ & $83,5 \%$ \\
\hline & Sem Informação & $0,8 \%$ & $0,3 \%$ \\
\hline & Técnico & $2,5 \%$ & $7,1 \%$ \\
\hline \multirow{3}{*}{ Trabalhava no momento do Ingresso } & Não & $55,8 \%$ & $63,3 \%$ \\
\hline & Sem Informação & $1,7 \%$ & $0,5 \%$ \\
\hline & Sim & $42,5 \%$ & $36,2 \%$ \\
\hline \multirow{8}{*}{ Idade no Ingresso } & 15 ou 16 anos & $0,8 \%$ & $0,3 \%$ \\
\hline & 17 anos & $21,0 \%$ & $19,1 \%$ \\
\hline & 18 anos & $26,9 \%$ & $25,7 \%$ \\
\hline & 19 anos & $15,1 \%$ & $13,4 \%$ \\
\hline & Entre 20 e 29 anos & $30,3 \%$ & $36,4 \%$ \\
\hline & 30 anos ou mais & $5,9 \%$ & $5,2 \%$ \\
\hline & Média (em anos) & 20,54 & 20,46 \\
\hline & Desvio Padrão & 5,11 & 4,81 \\
\hline
\end{tabular}

Fonte: Cadastro de Informações Sociais da Universidade (elaboração dos autores)

Quando se considera o tipo de instituição escolar dos prounistas no ensino médio, verifica-se que a maioria cursou escola pública, em sintonia com os critérios de elegibilidade do Programa. Todavia, os alunos do PBF parecem ser mais dependentes das instituições públicas em sua formação: $90,8 \%$, número 7,3 pontos acima em relação aos demais alunos. Essa diferença pode sugerir que os bolsistas do Prouni não PBF dispõem de maior êxito em estratégias educacionais que visem escapar da escola pública, conjugando-a com instituições particulares de maneira combinada ou exclusiva, visando possibilitar maior qualidade no ensino oferecido. Nesse sentido, os números daqueles que frequentaram instituições particulares dos demais alunos prounistas são sempre superiores em relação aos verificados no grupo PBF. 
PIRES, A.; ROMÃO, P. C. R.

As transições escolares, sobretudo para o ensino superior, são situações complicadas para alunos de diferentes grupos sociais. No entanto, alguns fatores, como dispor de mais tempo para dedicação aos estudos e ingressar em idade próxima em relação aos demais colegas, podem contribuir para facilitar essa passagem e suas respectivas adaptações. Por se tratar de grupos mais pobres, nota-se uma esperada proporção de prounistas que trabalhavam no momento de seu ingresso. Contudo, mais uma vez, a desvantagem recai para o grupo do $\mathrm{PBF}$, no qual $42,5 \%$ trabalhavam no momento do ingresso, ante $36,2 \%$ dos demais bolsistas (diferença de 6,3 pontos). Veremos adiante que esse é mais um indicativo do fato de que os alunos do PBF são, proporcionalmente, os principais responsáveis pelo sustento de suas famílias, tendo, portanto, a necessidade de conjugar trabalho e estudo.

Destaca-se que os alunos bolsistas ingressam na Universidade com uma idade média de 20,5 anos, um pouco acima, portanto, daquela esperada em um sistema de ensino seriado como o brasileiro, que é entre 17 e 18 anos. Tais números retratam as dificuldades enfrentadas por boa parte desses alunos no percurso escolar anterior ao ingresso na Universidade em termos, por exemplo, de interrupções (voluntárias e involuntárias) dos estudos, tentativas de ingresso em outras Instituições de Ensino Superior, reprovações, entre outros fatores. Para ambos os grupos (PBF e demais alunos) verifica-se que a maioria, 51,3\% e 54,9\% respectivamente, ingressou em idade acima da esperada (19 anos ou mais). No caso dos alunos que recebem o PBF, observa-se maior porcentagem de alunos mais velhos (acima de 30 anos) e maior desvio padrão.

Tabela 6: Distribuição dos alunos do Prouni segundo Área de Conhecimento do Curso de Graduação

\begin{tabular}{cl|r|r} 
& & \multicolumn{2}{c}{ Prouni } \\
& \multicolumn{2}{c}{ Bolsa Família } & Demais alunos \\
\hline \multirow{2}{*}{$\begin{array}{c}\text { Ciências Exatas e da Terra } \\
\text { Área do }\end{array}$} & Ciencincias Biológicas & $1,7 \%$ & $5,2 \%$ \\
\cline { 2 - 4 } & Engenharias & $3,3 \%$ & $3,5 \%$ \\
\cline { 2 - 4 } & Ciências da Saúde & $9,2 \%$ & $11,7 \%$ \\
\cline { 2 - 4 } & Ciências Sociais Aplicadas & $10,0 \%$ & $13,1 \%$ \\
\cline { 2 - 4 } & Ciências Humanas & $52,5 \%$ & $47,0 \%$ \\
\cline { 2 - 4 } & Linguística, Letras e Artes & $19,2 \%$ & $12,6 \%$ \\
\cline { 2 - 4 } & Outros & $2,5 \%$ & $5,6 \%$ \\
\cline { 2 - 4 } & SEM INFORMAÇÃO & $1,7 \%$ & $1,3 \%$ \\
\hline
\end{tabular}

Fonte: Cadastro de Informações Sociais da Universidade (elaboração dos autores)

No tocante à área de conhecimento, a Tabela 6 indica que $74,2 \%$ dos alunos Prouni/PBF cursam graduação nas áreas de Ciências Sociais Aplicadas, Ciências Humanas 
e Linguística, Letras e Artes. Considerando os demais alunos prounistas, a porcentagem diminui para $65,2 \%$. Na área das Engenharias, Ciências da Saúde e, sobretudo, Ciências Exatas e da Terra, verifica-se uma menor proporção de alunos do PBF em relação aos demais prounistas.

Tabela 7: Distribuição dos alunos do Prouni segundo Cursos de Graduação selecionados

\begin{tabular}{|c|c|c|c|}
\hline & & Prour & \\
\hline & & Bolsa Família & Demais alunos \\
\hline \multirow{20}{*}{ Cursos } & ADMINISTRAÇÃO & $20,8 \%$ & $14,4 \%$ \\
\hline & ENGENHARIAS & $9,2 \%$ & $11,7 \%$ \\
\hline & DIREITO & $8,3 \%$ & $10,5 \%$ \\
\hline & JORNALISMO & $5,8 \%$ & $2,4 \%$ \\
\hline & PEDAGOGIA & $5,0 \%$ & $2,1 \%$ \\
\hline & CIÊNCIAS CONTÁBEIS & $4,2 \%$ & $3,7 \%$ \\
\hline & CIÊNCIAS SOCIAIS & $4,2 \%$ & $1,7 \%$ \\
\hline & CIÊNCIAS BIOLÓGICAS & $3,3 \%$ & $3,5 \%$ \\
\hline & BIBLIOTECONOMIA & $3,3 \%$ & $2,6 \%$ \\
\hline & PSICOLOGIA & $3,3 \%$ & $4,1 \%$ \\
\hline & CIÊNCIAS ECONÔMICAS & $2,5 \%$ & $3,5 \%$ \\
\hline & ARQUITETURA E URBANISMO & $2,5 \%$ & $3,2 \%$ \\
\hline & $\overline{\text { FILOSOFIA }}$ & $2,5 \%$ & $1,4 \%$ \\
\hline & GEOGRAFIA & $2,5 \%$ & $1,5 \%$ \\
\hline & SISTEMAS DE INFORMAÇÃO & $1,7 \%$ & $2,7 \%$ \\
\hline & EDUCAÇÃO FÍSICA & $1,7 \%$ & $2,8 \%$ \\
\hline & PUBLICIDADE E PROPAGANDA & $1,7 \%$ & $2,7 \%$ \\
\hline & LETRAS PORTUGUÊS INGLÊS & $1,7 \%$ & $4,2 \%$ \\
\hline & MEDICINA & $0,8 \%$ & $3,3 \%$ \\
\hline & DEMAIS CURSOS* & $15,0 \%$ & $18,0 \%$ \\
\hline
\end{tabular}

Fonte: Cadastro de Informações Sociais da Universidade (elaboração dos autores) 
PIRES, A.; ROMÃO, P. C. R.

Verifica-se, pelas informações da Tabela 7, que, nos cursos mais prestigiados da Universidade, a saber, Engenharias, Direito, Psicologia, Arquitetura e Urbanismo e, sobretudo, Medicina, há proporção superior de prounista não PBF em comparação com aqueles que já receberam tal benefício. Entre os que recebem ou já receberam o $\mathrm{PBF}$, notase o peso dos cursos de Administração, Ciências Contábeis e, sobretudo, os cursos de licenciaturas. Agrupados, os alunos matriculados em cursos de licenciaturas (Ciências Sociais, Ciências Biológicas, Filosofia, Geografia, Pedagogia e Letras) compõem 19,2\% do grupo PBF, ante $14,4 \%$ dos demais prounistas. A opção pelas licenciaturas pode ser expressão da escolha pelo possível, não pelo desejado. Nas palavras de Amaral e Oliveira

Conforme afirmado por Gatti e Barreto (2009), a escolha da docência é uma espécie de plano B ou "seguro desemprego", isto é, figura como uma alternativa no caso de não haver possibilidade de exercício de outra atividade. Segundo pesquisa realizada pelas autoras, apenas $2 \%$ dos estudantes do ensino médio tem como primeira opção no vestibular graduações relacionadas à atuação em sala de aula. No Sistema de Seleção Unificada (Sisu) de 2009, dos cem cursos com as notas de corte mais baixas, 75 são de licenciatura (AMARAL; OLIVEIRA, 2011, p. 885).

Tabela 8: Distribuição dos alunos do Prouni segundo Período dos Cursos de Graduação

\begin{tabular}{|c|c|c|c|}
\hline & & \multicolumn{2}{|c|}{ Prouni } \\
\hline & & Bolsa Família & Demais alunos \\
\hline \multirow{4}{*}{ Período } & Matutino/Vespertino & $10,8 \%$ & $16,1 \%$ \\
\hline & Matutino & $29,2 \%$ & $28,3 \%$ \\
\hline & Noturno & $60,0 \%$ & $54,2 \%$ \\
\hline & Vespertino/Noturno & $0,0 \%$ & $1,3 \%$ \\
\hline
\end{tabular}

Fonte: Cadastro de Informações Sociais da Universidade (elaboração dos autores)

As informações da Tabela 8 mostram, em consonância com os cursos de graduação selecionados (Tabela 7), que a maioria dos alunos do Prouni, seja ex-bolsista do PBF ou não, está matriculado em curso de um único período (matutino ou noturno). No caso dos alunos do PBF, verifica-se elevada proporção de alunos em cursos noturnos ( $60 \%$, ante $54,2 \%$ para os demais alunos), provavelmente decorrente do peso dos cursos de licenciaturas para esse grupo, oferecidos em sua maioria no período noturno na Universidade em questão. Ademais, veremos que alunos do PBF trabalham mais e são os maiores responsáveis pela contribuição da renda familiar. Para quem trabalha e estuda, fica mais difícil frequentar cursos em período integral. Nesse sentido, compreendem-se as razões para que um número maior de prounistas não Bolsa Família façam cursos integrais, $17,4 \%$ ante $10,8 \%$. Essa diferença faz com que um número reduzido de prounistas do grupo PBF possa pleitear Bolsa Permanência, benefício previsto no desenho do Prouni para alunos cuja carga horária média de seu curso de graduação seja igual ou superior a 
6 (seis) horas diárias de aula. Andrade e Sposito (1986) apontam que o trabalho, mais do que o estudo, é fator decisivo para uma questão de sobrevivência familiar, conduzindo os alunos aos períodos em que possam conciliar trabalho e estudos com mais facilidade. Sampaio, Limongi e Torres $(2000$, p. 36) nos mostram que "o trabalho em período integral é mais frequente entre os formandos de renda familiar mais baixa ( 0 a 10 salários mínimos) e os oriundos de instituições privadas (universidades e estabelecimentos não universitários)", tais como os entrevistados em nossa pesquisa.

Tabela 9. Trabalho e rendimentos

\begin{tabular}{clr|r} 
& \multicolumn{2}{c}{ Prouni } \\
& & Bolsa Família & Demais alunos \\
\hline \multirow{3}{*}{ Condição de Moradia Atual } & Alugada & $27,5 \%$ & $19,8 \%$ \\
\cline { 2 - 4 } & Cedida & $15,8 \%$ & $16,0 \%$ \\
\cline { 2 - 4 } & Financiada & $4,2 \%$ & $5,8 \%$ \\
\cline { 2 - 4 } & Própria & $50,8 \%$ & $58,1 \%$ \\
\cline { 2 - 4 } & Sem Informação & $1,7 \%$ & $0,3 \%$ \\
\hline \multirow{2}{*}{ Com quem reside } & Amigos (república) & $20,8 \%$ & $14,7 \%$ \\
\cline { 2 - 4 } & Família & $68,3 \%$ & $73,9 \%$ \\
\cline { 2 - 4 } & Outros & $2,5 \%$ & $2,2 \%$ \\
\cline { 2 - 4 } & Parentes & $4,2 \%$ & $4,8 \%$ \\
\cline { 2 - 4 } & Sem Informação & $3,3 \%$ & $0,2 \%$ \\
\cline { 2 - 4 } & Sozinho & $4,2 \%$ \\
\hline
\end{tabular}


PIRES, A.; ROMÃO, P. C. R.

\begin{tabular}{|c|c|c|c|}
\hline \multirow{16}{*}{ Trabalho ou Fonte de Renda do Pai } & Aposentado & $5,0 \%$ & $7,7 \%$ \\
\hline & Atividade Rural & $0,8 \%$ & $0,4 \%$ \\
\hline & Autônomo & $0,8 \%$ & $3,7 \%$ \\
\hline & Beneficiário do INSS & $1,7 \%$ & $0,6 \%$ \\
\hline & CLT & $13,3 \%$ & $22,2 \%$ \\
\hline & Concursado & $0,8 \%$ & $2,7 \%$ \\
\hline & Desempregado & $2,5 \%$ & $3,8 \%$ \\
\hline & Informal & $17,5 \%$ & $10,1 \%$ \\
\hline & Liberal & $0,0 \%$ & $1,4 \%$ \\
\hline & $\begin{array}{l}\text { Não faz parte do grupo } \\
\text { familiar }\end{array}$ & $50,0 \%$ & $37,7 \%$ \\
\hline & Pensionista & $0,0 \%$ & $0,4 \%$ \\
\hline & Proprietário de Empresa & $0,8 \%$ & $2,3 \%$ \\
\hline & Renda - & $0,0 \%$ & $0,2 \%$ \\
\hline & Aluguel/Arrendamento & & \\
\hline & Sem informação & $5,0 \%$ & $6,5 \%$ \\
\hline & Sem Renda & $1,7 \%$ & $0,5 \%$ \\
\hline
\end{tabular}




\begin{tabular}{|c|c|c|c|}
\hline \multirow{18}{*}{ Trabalho ou Fonte de Renda da Mãe } & Aposentado & $2,5 \%$ & $4,9 \%$ \\
\hline & Atividade Rural & $0,0 \%$ & $0,1 \%$ \\
\hline & Autônomo & $0,8 \%$ & $1,3 \%$ \\
\hline & Beneficiário do INSS & $3,3 \%$ & $0,6 \%$ \\
\hline & CLT & $21,7 \%$ & $24,5 \%$ \\
\hline & Concursado & $3,3 \%$ & $8,7 \%$ \\
\hline & Desempregado & $7,5 \%$ & $7,1 \%$ \\
\hline & Do Lar & $24,2 \%$ & $20,3 \%$ \\
\hline & Estagiário & $0,0 \%$ & $0,1 \%$ \\
\hline & Informal & $16,7 \%$ & $10,4 \%$ \\
\hline & Liberal & $0,0 \%$ & $0,6 \%$ \\
\hline & $\begin{array}{l}\text { Não faz parte do grupo } \\
\text { familiar }\end{array}$ & $11,7 \%$ & $14,8 \%$ \\
\hline & Pensionista & $2,5 \%$ & $2,6 \%$ \\
\hline & Proprietário de Empresa & $2,5 \%$ & $1,3 \%$ \\
\hline & Renda - & $0,8 \%$ & $0,3 \%$ \\
\hline & Aluguel/Arrendamento & & \\
\hline & Sem informação & $2,5 \%$ & $2,0 \%$ \\
\hline & Sem Renda & $0,0 \%$ & $0,6 \%$ \\
\hline \multirow{12}{*}{$\begin{array}{l}\text { Quem é a pessoa responsável pela } \\
\text { maior contribuição na renda }\end{array}$} & Aluno & $25,0 \%$ & $14,8 \%$ \\
\hline & Avó & $0,8 \%$ & $2,4 \%$ \\
\hline & Avô & $0,8 \%$ & $1,1 \%$ \\
\hline & Cônjuge & $5,0 \%$ & $3,5 \%$ \\
\hline & Irmão(ã) & $10,8 \%$ & $6,5 \%$ \\
\hline & Madrasta & $0,0 \%$ & $0,2 \%$ \\
\hline & Mãe & $21,7 \%$ & $26,6 \%$ \\
\hline & Outros & $1,7 \%$ & $1,4 \%$ \\
\hline & Padrasto & $6,7 \%$ & $2,6 \%$ \\
\hline & Pai & $26,7 \%$ & $39,2 \%$ \\
\hline & Sem informação & $0,8 \%$ & $0,7 \%$ \\
\hline & Tio(a) & $0,0 \%$ & $1,1 \%$ \\
\hline \multirow{2}{*}{ Renda Bruta do Grupo Familiar } & Média (em R\$) & 1537,57 & 1722,54 \\
\hline & Desvio Padrão & 2035,162 & 1321,954 \\
\hline
\end{tabular}

Fonte: Cadastro de Informações Sociais da Universidade (elaboração dos autores) 
Ao analisarmos as condições de moradia atual, atentamos para o fato de que os alunos do Prouni são menos dependentes de pagamento de sua moradia em relação aos alunos que participaram do PBF: quanto à moradia própria, temos uma diferença de cerca de 8 pontos percentuais dos alunos não beneficiários do $\mathrm{PBF}$ em relação aos demais. Ao observarmos os alunos com residências alugadas, notamos uma diferença similar: $27,5 \%$ dos alunos PBF, ante 19,8\% dos demais alunos. Deste modo, são necessárias estratégias de acumulação e organização da renda de maneira a sanar despesas relativas à moradia e, ainda assim, continuar seus estudos. Convém ainda lembrarmos que, de acordo com informações da tabela 4, os alunos do PBF apresentam grupos familiares de origens bastante distantes da cidade onde se encontra a instituição, o que os leva a ter de conseguir moradia próxima à instituição pesquisada, mesmo que isso exija algum tipo de esforço extra. Destaca-se que o Prouni proporciona auxílio-moradia, por meio da Bolsa Permanência, apenas no caso de cursos com mais de seis horas diárias de aula, o que não acontece na maioria dos cursos nos quais os alunos prounistas estão matriculados. Consoante com tais reflexões, notamos que uma das estratégias utilizadas pelos alunos PBF para conseguir moradia é por meio das repúblicas $(20,8 \%$, ante $14,7 \%$ dos demais bolsistas), forma pela qual podem dividir gastos e poupar renda.

Considerando dados sobre a fonte de renda dos pais, rememoramos a já discutida questão da maternagem: um número maior dos alunos oriundos do $\mathrm{PBF}(50,0 \%$, ante $37,7 \%$ dos demais alunos) não apresenta os pais como membros do grupo familiar, ou seja, as famílias são, na maioria das vezes, chefiadas por mulheres, beneficiárias diretas do programa (PIRES, 2013b). Notamos que as fontes mais estáveis de renda, como aposentadoria, trabalho com carteira de trabalho assinada ou transferências do INSS são menores no caso dos alunos que foram beneficiários do $\mathrm{PBF}$, em relação às fontes de renda como trabalho informal ou autônomo. Assim, esses alunos, ao não contarem com subsídios oriundos de rendas estáveis no decorrer de suas trajetórias, necessitam de estratégias específicas para arcar com os custos de manterem-se nos cursos, seja por meio de outras formas de complementação da renda, seja pela economia daquela que obtiveram, e correm o risco de não possuírem esses recursos nos meses subsequentes.

Quanto às mães, verificamos aproximadamente o mesmo fenômeno: a maior parte da renda é oriunda de formas não-estáveis. De modo similar aos pais, possuem um número maior de fontes de renda, por exemplo, trabalho informal $(16,7 \%$ das mães beneficiárias do PBF, ante $10,4 \%$ das mães dos demais alunos). É importante notarmos que a figura materna se mostra muito mais presente como integrante do grupo familiar do que os pais ( $50,0 \%$ dos pais, no caso dos alunos do $\mathrm{PBF}$, não fazem parte do grupo, ante apenas $11,7 \%$ das mães no mesmo caso), o que implica numa diminuição da acumulação de renda por parte dessas famílias, ao contarem apenas com a figura materna na maioria dos casos. Com isso, podemos inferir que existe um esforço muito maior por parte dessas famílias para manterem-se sem as garantias que uma fonte de renda estável pode proporcionar, o que pode afetar diretamente os alunos ao buscarem conjugar o trabalho e formas de sustentar o lar aos seus estudos.

As pesquisas na área apresentam resultados parecidos: Almeida (2014) aponta para o fato de que a maior parte dos pais ocupa profissões demarcadas sobremaneira por trabalhos manuais, enquanto as mães, em sua maioria, ocupam-se de profissões domésticas. Cabe ressaltar ainda que as possibilidades de melhoria das condições 
socioeconômicas dos alunos são tão frágeis quanto a de seus pais, devido à necessidade de conciliar estudos e trabalho:

Um primeiro aspecto a destacar refere-se às relações contratuais frágeis encontradas e destacadas nos três subconjuntos. Assim, despontam termos como "terceirizado", "bicos", "temporário", "freelancer" e, também, vários relatos em que o/a bolsista esteve trabalhando "sem registro", além de uma miríade de "trabalhos informais" no setor de prestação de serviços (ALMEIDA, 2014, p. 160).

Nessa perspectiva, notamos que é justamente o aluno o maior responsável pela contribuição da renda familiar, em especial no caso dos alunos do PBF: $25,0 \%$, ante $14,8 \%$ dos demais alunos. É exigido deles, portanto, um esforço adicional de estudar e gerar renda para ele e sua família quando comparados com os demais bolsistas. Ao analisarmos tais dados junto aos dados da renda bruta familiar, notamos que as fontes de renda menos estáveis e a menor contribuição dos familiares implica em uma renda bruta menor (12\% inferior na comparação com os bolsistas Prouni) e um desvio-padrão maior diante dos demais alunos.

\section{CONSIDERAÇÕES FINAIS}

O Prouni tem alcançado bons resultados no que diz respeito ao acesso ao ensino superior por parte de um grupo social até então distante dessa possibilidade, como atestam vários trabalhos (RISTOFF, 2016; ALMEIDA, 2014). Todavia, o custo para ingressar e permanecer no ensino superior, a se julgar pelas informações apresentadas nas páginas anteriores, parece ser um pouco mais alto quando se considera somente os bolsistas prounistas do grupo PBF: eles são a principal fonte de renda de seu grupo familiar (o qual, na maioria das vezes, está bastante distante da instituição de ensino, não só em termos econômicos quanto geográficos), e suas trajetórias educacionais mostram-se deveras mais exaustivas em relação àquelas dos demais alunos, devido à necessidade de manterse em seus estudos e trabalho. A questão da permanência é, talvez, um dos grandes problemas ao se analisar o Prouni, como já apontaram muitos estudos.

Notamos ainda que são necessárias diversas estratégias de superação de suas condições socioeconômicas originais para que os alunos do PBF possam manter-se na Universidade, tais como bolsas de estudo e de permanência (essas, no caso específico do Prouni, apresentando-se bastante improvável para a maioria dos cursos), trabalho no contraperíodo do curso $(25 \%$ dos alunos beneficiários do PBF mostram-se como responsável pela maior contribuição da renda) ou formas de moradia compartilhada, de modo a reduzir despesas.

A própria seleção dos cursos parece adequar-se à realidade desses alunos: a opção por cursos de licenciatura é feita por uma boa parcela. Mesmo acreditando na Educação como uma possibilidade de mudança na qualidade de vida, o acesso a cursos tidos como de maior prestígio, tais como Medicina ou Engenharia, ainda mostra-se distante da maioria dos alunos provenientes do grupo PBF. 
PIRES, A.; ROMÃO, P. C. R.

Os resultados da análise do perfil socioeconômico dos alunos beneficiários do Programa Bolsa Família que superaram, por assim dizer, os obstáculos que surgiram em suas trajetórias educacionais, abrem um novo panorama para a avaliação e aprimoramento de programas que busquem a redução do círculo intergeracional da pobreza por meio da Educação, especialmente ao vislumbrar a tão sacrificada trajetória desses alunos, que conseguiram atingir destinos até então improváveis para outros em condições semelhantes.

Artigo recebido em: 26/10/2018

Aprovado para publicação em: 18/12/2018

\title{
THE SOCIOECONOMIC PROFILE OF PROUNI STUDENTS AND FORMER BENEFICIARIES OF THE BOLSA FAMÍLIA PROGRAM OF A NON-PROFIT UNIVERSITY OF SÃO PAULO
}

\begin{abstract}
This article aims to describe, in a descriptive way, the socioeconomic profile of a small group of people who were beneficiaries of the Bolsa Família Program (PBF) and who enrolled in a private nonprofit University of São Paulo by Prouni. The enrollment numbers of this University indicate that those who receive or have already received PBF resources make up the group that is probably more vulnerable in socioeconomic terms. The article offers contributions in order to highlight the access to higher education of a social group that until then was far from this possibility, seeking to know the socioeconomic profile of the students originating from the Family Grant Program after Basic Education. However, the cost for this is particularly high when considering only the scholarship recipients and the Bolsa Família Program.
\end{abstract}

KEYWORDS: Prouni. Bolsa Família. Higher Education. Poverty.

\section{EL PERFIL SOCIOECONOMICO DE ALUMNOS DEL PROUNI Y EX BENEFICIARIOS DEL PROGRAMA BOLSA FAMILIA DE UNA UNIVERSIDAD SIN FINES DE LUCRO DE SÃO PAULO}

RESUMEN: Este artículo objetiva presentar, de manera descriptiva, el perfil socioeconómico de un conjunto reducido de personas que fue beneficiario del Programa Bolsa Familia (PBF) y que ingresó en una Universidad privada sin fines de lucro del estado de São Paulo por el Prouni. Los números del registro de esta Universidad indican que aquellos que reciben o ya recibieron recursos del PBF, son el grupo probablemente más vulnerable en términos socioeconómicos. Al buscar conocer el perfil socioeconómico de los alumnos originarios del Programa Bolsa Familia después de la Educación Básica, el artículo ofrece contribuciones en el sentido de evidenciar el acceso a la enseñanza superior de un grupo social hasta entonces distante de esa posibilidad. Sin embargo, el costo para ello se muestra particularmente alto cuando se considera solamente a los becarios y ex becarios del Programa Bolsa Familia.

PALABRAS CLAVE: Prouni. Bolsa Familia. Enseñanza Superior. Pobreza. 


\section{NOTAS}

1) Escaparia das intenções do texto discorrer sobre as críticas à teoria do capital humano que, no plano educacional, parece reduzir a formação da pessoa à aquisição de um conjunto de habilidades e destrezas dirigido ao mercado de trabalho. Sobre os paradoxos relativos à falta de humanidade presente nessa concepção, que mensura a existência humana pelos valores do mercado, consultar Fonseca (2009).

2) Embora relevante, não serão analisadas neste artigo críticas formuladas a esses programas, as quais não negam a importância dessas iniciativas no sentido de propiciar aumento no número de matrículas para alunos de baixa renda nas IES (Instituições de Ensino Superior) privadas ou públicas, todavia, evidenciam alguns problemas. Sem ter a pretensão de esgotar esse tema, seguem duas críticas principais: a) de que os recursos públicos transferidos às IES privadas, caso do Fies, poderiam ser aplicados na melhoria das IES públicas; b) de que o resultado destas iniciativas proporcionou uma massificação do ensino superior, em detrimento de uma desejada democratização do acesso e permanência no ensino superior. $O(a)$ leitor(a) poderá obter maiores informações a respeito dessas críticas em Prates; Barbosa (2015); Dubet (2015); Catani, Hey, Gilioli (2006), entre outros. Almeida (2014), por exemplo, problematiza a própria criação do Prouni, apontando que o programa surge para atender demandas das Instituições de Ensino Superior privadas com fins lucrativos e não, como se supõe à primeira vista, para promover maior acessibilidade a essa modalidade de ensino para as classes sociais menos favorecidas. Santana $(2009$, p. 61) afirma que “...a preocupação central do programa parece não ser a equidade. O programa possui uma lógica econômica, contábil, que acaba tendo por consequência o acesso da população ao ensino superior".

3) No caso do Programa Bolsa Família, sua gestão compete ao Ministério do Desenvolvimento Social e Agrário. Já o Prouni é gerido pelo Ministério da Educação.

4) Agradecemos o empenho dos gestores desse órgão. De acordo com a Declaração de Sigilo para Utilização de Informações Socioeconômicas, avaliado pelo Comitê de Ética em Pesquisa com Seres Humanos da Universidade, não foram divulgadas informações que permitam identificar a Universidade e/ou os alunos.

5) Endereço: http://portal.inep.gov.br/web/guest/censo-da-educacao-superior, acesso em $25 / 10 / 2018$

6) Endereço: http://portal.inep.gov.br/web/guest/microdados, acesso em 04/07/2017.

7) Essa terminologia é utilizada no questionário socioeconômico da Universidade pesquisada.

8) Termos utilizados para atribuição de cor e raça do questionário do Estudante do Enade nos anos considerados.

9) De maneira similar, pesquisas de Costa (2008) e Santos (2011), ambas realizadas em universidades confessionais, apresentam os pais com níveis escolares relativamente baixos, ou seja, até a conclusão do ensino fundamental. Tal dado mostra-se relevante ao compor o perfil dos alunos bolsistas: muitas vezes, esses são os primeiros a adentrar o ensino superior em suas famílias. 
PIRES, A.; ROMÃO, P. C. R.

\section{REFERÊNCIAS}

ABRAHÃO, J.; MOSTAFA, J.; HERCULANO, P. Gastos com a Política Social: alavanca para o crescimento com distribuição de renda. Rio de Janeiro: Comunicados número 75 do Instituto de Pesquisa Economia Aplicada (IPEA), 2011.

ALMEIDA, W. M. D. ProUni e o ensino superior provado lucrativo em São Paulo: uma análise sociológica. São Paulo: Editora Musa/Fapesp, 2014.

AMARAL, D. P. D.; OLIVEIRA, B. F. O Prouni e a conclusão do ensino superior: novas trajetórias pessoais e profissionais dos egressos. Ensaio: aval. pol. públ. Educ, Rio de Janeiro, v. 19, n. 73, p. 861-890, 2011.

ANDRADE, C. L. D.; SPOSITO, M. P. O aluno do curso superior noturno: um estudo de caso. Cadernos de Pesquisa (Fundação Carlos Chagas), São Paulo, v.57, 1986. 3-19.

CASALI, A. M. D.; MATTOS, M. J.V.M. Análise de estudos e pesquisas sobre o sentido social do programa Universidade para Todos (PROUNI). Ensaio, v.23, n. 88, p. 681-716, 2015.

CATANI, A. M.; HEY, A. P.; GILIOLI, R. S. P. PROUNI: democratização do acesso às Instituições de Ensino Superior? Educ. rev. [online], p. n.28, 125-140, 2006.

CIRENO, F.; SILVA; PROENÇA, B. Condicionalidades, desempenho e percurso escolar de beneficiários do Programa Bolsa Família. In: CAMPELLO, T; NERI, M. Programa Bolsa Família: uma década de inclusão e cidadania. Rio de Janeiro: Instituto de Pesquisa Econômica Aplicada (IPEA), 2013.

COSTA, F. Políticas Públicas de Educação Superior - Programa Universidade para Todos: um olhar dos alunos beneficiários da PUC-SP. São Paulo: Pontifícia Universidade Católica de São Paulo, 2008.

DUBET, F. Qual democratização do ensino superior? Cadernos $C R H$, Salvador, v. 28, n. 74, p. 255-265, Maio/Ago 2015.

FONSECA, A. M. Família e Política de Renda Mínima. São Paulo: Cortez, 2001.

FONSECA, A. M. M. D. Transferencias condicionadas, estrategias de combate al hambre y la desnutricion en America Latina y el Caribe. Santiago: FAO, 2009.

GONÇALVES, G. Q.; MENICUCCI, G. T. M.; AMARAL, F. L. E. Diferencial educacional entre beneficiários e não beneficiários do Programa Bolsa Família. Cadernos de Pesquisa, no 165 jul./set. 2017. 770-795. 
MELO, R. D. M. S.; DUARTE, B. G. Impacto do Programa Bolsa Família sobre a frequência escolar: o caso da agricultura familiar no Nordeste do Brasil. Revista de Economia e Sociologia Rural, p. vol. 48, n03, p. 635-656, 2010.

PIRES, A. Bolsa Família e Políticas Públicas Universalizantes: o caso de um município paulista. Cadernos de Pesquisa (Fundação Carlos Chagas), São Paulo, v. 38, 2008. 341 366.

PIRES, A. Orçamento familiar e gênero: percepções do Programa Bolsa Família. Cadernos de Pesquisa, vol.42, n.145., 2012. 130-161.

PIRES, A. Efeitos da Condicionalidade em Educação do Programa Bolsa Família em Campinas (SP). São Paulo, Estudos em Avaliação Educacional, 2013b. no 55, no prelo.

PRATES, A. A. P.; BARBOSA, M. L. D. O. A expansão e as possibilidades de democratização do ensino superior no Brasil. Caderno $C R H$, Salvador, v. 28, n. 74, p. 327-347, Maio/Ago 2015.

QUESTÃO de Oportunidade. Direção: Ana Fonseca. [S.I.]: [s.n.]. 2017.

REGO, W. L.; PINZANI. Vozes do Bolsa Família: autonomia, dinheiro e cidadania. São Paulo: Editora da Unesp, 2013.

RISTOFF, D. Democratização no Campus: impactos dos programas de inclusão sobre o perfil da graduação. Cadernos GEA, n.9, 2016.

ROCHA, S. Transferências de renda no Brasil: o fim da pobreza? Rio de Janeiro: Elsevier, 2013.

SAMPAIO, H.; LIMONGI, F.; TORRES, H. Equidade e Heterogeneidade no Ensino Superior Brasileiro. Brasília: Inep, 2000.

SANTOS, C. T. A. Chegada ao Ensino Superior: o caso dos bolsistas do Prouni da PUC-Rio. Rio de Janeiro: Universidade Federal do Rio de Janeiro, 2011.

SANTOS, C. T. Permanência de Bolsistas do ProUni no ensino superior. In: HONORATO, G.; HERINGER, R. Acesso e Sucesso no Ensino Superior: uma Sociologia dos Estudantes. Rio de Janeiro: 7 Letras/Faperj, 2015.

SILVA, M. O. D. S.; YAZBEK, M. C.; DI GIOVANNI, G. A Política Brasileira no Século XXI: a prevalência dos programas de transferência de renda. São Paulo: Cortez, 2007. 
PIRES, A.; ROMÃO, P. C. R.

SILVA, M. O. S. E. O Bolsa Familia no Enfrentamento à Pobreza no Maranhão e Piauí. São Paulo: Cortez, 2013.

André PIRES: Graduado em Ciências Sociais (Unicamp). Mestre em Antropologia Social (Unicamp). Doutor em Ciências Sociais (Unicamp). Pós-Doutoramento (Universidade de Princeton). Professor titular do Programa de Pós-Graduação em Educação da PUCCampinas.

Orcid: http://orcid.org/0000-0002-8344-7662

E-mail: anpires@gmail.com

Paulo Cesar Ricci Romão: Mestre pelo Programa de Extensão e Pós-Graduação na área de Políticas Públicas em Educação na Pontifícia Universidade Católica de Campinas. Possui graduação em Letras - Inglês pelo Centro Universitário UNIFEOB (2007) e pós-graduado em Língua Portuguesa e Literatura pela Universidade Cândido Mendes (2014).

E-mail: promaoster@gmail.com.

Este periódico utiliza a licença Creative Commons Attribution 3.0, para periódicos de acesso aberto (Open Archives Iniciative - OAI). 